\title{
A Case Study on Ni based Super Alloys Ageing for Improvement of its Properties
}

\author{
Dr. Nripjit ${ }^{1}$, Sunil Kumar ${ }^{2}$ \\ Beant College of Engg. \& Technology, Gurdaspur ${ }^{1,2}$
}

\begin{abstract}
Few studies have been done on the investigation of aging process of Ni based super alloys. There is a need of more investigation to control the above process by using aging at different temperature for different durations of time. It is also found from the study that microstructure, physical and mechanical properties of material depend on temperature, time and quenching medium. In the present work, effect has been made to study the methods of improving the hardness, strength and other properties of the super alloy.
\end{abstract}

Key words: Super-alloys, Carbon based super-alloys, ageing and heat treatment, etc.

\section{INTRODUCTION}

Super alloys are heat-resistant alloys, today used in high temperature and corrosion-resistant applications in a variety of industries. The development of gas turbines has been the main driving force for the existence of the super alloys. Super alloys are heat-resistant alloys of nickel, nickel- iron, or cobalt that exhibit a combination of mechanical strength and resistance to surface degradation generally unmatched by other metallic compounds. The primary uses of these alloys are in: Aircraft gas turbines, disks, combustion chambers, bolts, castings, shaft exhaust systems, blades, vanes, etc. Steam turbine power plants, bolts, blades, stack gas re- heaters, Reciprocating engines, turbocharger, exhaust valves, hot plugs, Metal processing, hot work tool and dies, casting dies, Medical applications, e.g. dentistry uses, prosthetic devices., Space vehicles, Heat-treating equipment, Nuclear power systems, Chemical and petrochemical industries, Pollution control equipment and Coal gasification and liquefaction systems. Super alloys are divided into three classes: nickel-based, cobalt based and iron-nickel-based alloys. The nickelbased super alloys are the super alloys most frequently used in gas turbine components. These super alloys $(\mathrm{Ni}$, $\mathrm{Fe}-\mathrm{Ni}$, and Co-base) are further sub-divided into wrought, cast, and powder metallurgy alloys. Nickel-base alloys contain at least $50 \%$ nickel, whereas in nickel-iron base alloy, nickel is the major solute component.

\section{LITERATURE SURVEY}

This section provides details of earlier research carried out on measuring the effect of property of super alloy various temp conditions. There is enormous information available on the theoretical and experimental work related to the heat treatment of super alloy which is discussed as follows.

I.A. Choudhury et al. [1] has studied on Nickel-base super alloys and found that in conel has a poor mach inability. Because of their high hardness, high strength at high temperature, and low thermal diffusivity. This paper presents a general review of their different types of properties and material characteristics together with their mach inability assessment when using different cutting tools. Also discuss the merits and demerits of different tool materials during the machining.

Furrer et al. [2] have discussed the optimum method to optimizing the heat treatment of nickel based super alloy. Heat treatment of nickel based super alloy continues to change due to development of new alloy, new requirement and subsequent new manufacturing facilities. Being optimized for numerous mechanical and physical properties and increasing the challenges the selection of heat treatment parameters. (Parameter like cooling rate, cooling path) The cooling rate and cooling path imposed on nickel-based super alloy components is key and critical to the development of optimum properties. Typically, higher cooling rates allow an increase in mechanical properties, but are often accompanied by an increase in unacceptable component internal residual stresses. Wangyao et al. [3] have provided the new method of repairing the super alloy and the reestablishment of the initial properties and near original microstructure of the long term used or damaged parts for the economic reasons. The alloys standard heat treatment not effective when applied long-term serviced microstructure to reestablishment of mechanical properties. Due to this reasons hot isostatic pressing (HIP) is applied before the reheat treatment then an effective way to incorporate the high temperature cycle is needed to restore the serviced microstructure and found that the high temperature used at during the HIP process also assists to homogenize the microstructure. The rejuvenation process provides blades to double and in some cases, triple the lifetime as compared to the original ones. M. Pollock et al. [4] Nickel-based super alloys are an exceptional class of structural materials for high-temperature applications and the particularly challenging environment of the turbine section of the aircraft engine. The aim of this paper is to review the characteristics (like chemical, physical, mechanical etc) of super alloy used in turbine engine. Also discussed the role of major and minor alloying, multi component commercial cast and wrought super alloys Experimentally revealed that micro structural stability and phases observed during processing and in subsequent 
elevated-temperature service are summarized. Neal D. heating on the $1240{ }^{\circ} \mathrm{C}$ with $2 \mathrm{~h}$ temperature dwell, so that Evans et al. [5] described an experimental investigation on precipitates dissolved completely at the grain boundaries. the cost effective materials, microstructure, temperature Subsequently, slow cooling down to the temperature of capability and performance limitations of exhaust $940-950{ }^{\circ} \mathrm{C}$ leads to intensive intra granular precipitation components used ARES. Wrought $\mathrm{Ni}$ based and heat of intermetallic $\gamma^{\prime}$ phase. Mohamed Retima et al. [9] treated super alloy (Pyromet 31V) used in exhaust valve. discussed the effect of heat treatment on the formation and Pyromet $31 \mathrm{~V}$ have been examined both as manufactured precipitation of different micro structural features in a condition and $2400 \mathrm{~h}$ in actual service. Service cobalt-rich nickel based super alloy similar to Udimet 500 temperatures were estimated for the various valves at 650- was studied by SEM and TEM. The choice of heat $700^{\circ} \mathrm{C}$. experimentally found that In the fresh condition, treatment type has to be adjusted according required the base material of the valve can be described as having a properties. The aim of this study was to investigate the $\gamma$ matrix that is strengthened by $\gamma$ ' precipitates, with formation and evolution of different phases .The $\gamma$ matrix M23C6 carbides residing along grain boundaries and MC is FCC solid solution in which the particles of the $\gamma$ ' FCC carbides present within the austenite. During service, the microstructure under transformations which shows the lacking of mechanical properties of alloy, $\gamma^{\prime}$ precipitates coarsening, precipitates alpha-Cr within the austenite grains. Timothy P. et al. [6] have assessed the effects of heat treatment on a powder metallurgy disk super alloy LSHR and identify the micro structure variations, mechanical properties on high temperature. Work were consistently super solvus solution heat treated and quenched at two cooling rates, than aged at varying temperatures and times. Tensile, creep, and dwell fatigue crack growth tests were then performed at $704^{\circ} \mathrm{C}$. and observed that grain boundaries were more serrated for slow cooled samples, but did not appear in vary with aging heat treatment High cooling rates were combined with aging at low temperatures to produce a high volume fraction of uniform, fine $\gamma \mathrm{S}^{\prime}$ combined with a low volume fraction of uniform, fine $\gamma \mathrm{T}^{\prime}$. This microstructure gave relatively high strength and creep resistance, but relatively low ductility and dwell fatigue crack growth resistance and vice versa. Samples of high cooling rate with subsequent high temperature aging experienced rapid reductions in $\gamma \mathrm{T}^{\prime}$ volume fraction, with corresponding increases in $\gamma \mathrm{S}^{\prime}$ volume fraction and some joining of nearby $\gamma \mathrm{S}^{\prime}$ precipitates. L.A. Dobrzañski et al. [7] the goal of this paper was study the influence of temperature and time in the age-hardening on the selected mechanical properties and hardness of the AlSi9Mg alloy.

The efficiency of the age-hardening were tested on laboratory specimens through the statically tension test on ZWICK/Z100. Damages were critically assessed through SEM investigations. Evaluation the mechanical properties of prepared samples were realized by solutioning and then ageing in different periods of time. Then adequately selected time of the ageing improved the hardening and plasticity and reduces the tendency of aluminum to formation of coagulations. JONSTA et al. [8] have discussed that nickel super alloy IN713LC, used as blade materials of jet engines turbines due to high strength even at very high temperature, resistance to fatigue effect of combustion gases etc. blades have main requirement is operational reliability and safety at high temperatures. These requirements directly linked to the microstructure, or with its stability at long-term exploitation. But IN713LC has heterogeneous microstructure with distinct dendritic segregation in as cast state. To overcome the heterogeneity given the optimum heat treatment including phase with an ordered structure formed. The $\gamma^{\prime}$ phase is primarily rate during oil quenching from $1150^{\circ} \mathrm{C}$. Primary carbides and secondary carbides are also formed at grain boundaries. Nader El-Bagoury et al .[10] have compared the microstructure and mechanical properties of super alloy when aging at $845^{\circ} \mathrm{C}$ for $24 \mathrm{~h}$ and solution treated at 1120 and $1180^{\circ} \mathrm{C}$ followed by air cooling before aging process and also manufactured or casted under various conditions of cooling rate and superheat. And found that volume fraction of TCP phase decreases with increasing casting superheat and lowering cooling rate. The grain size of aged specimens and solution treated at $118^{\circ} \mathrm{C}$ is coarser than ones solution treated at $1120^{\circ} \mathrm{C}$. and $\mathrm{V}_{\mathrm{f}}$ of $\gamma^{\prime}$ particles reduced in case of aged with high superheat specimen than that of low super heat one after solution at $112^{\circ} \mathrm{C}$ and $118^{\circ} \mathrm{C}$. Hardness measurements of aged alloys with low and high superheat specimen's solution treated at $1120^{\circ} \mathrm{C}$ are higher than that of $1180^{\circ} \mathrm{C}$. The $\mathrm{V}_{\mathrm{f}}$ of $\gamma^{\prime}$ in case of aged and solution treated at $1180^{\circ} \mathrm{C}$ is lower than that aged with solution treated at $1120^{\circ} \mathrm{C}$. N. El-Bagoury et al. [11] have manufactured super alloys by investment casting under various conditions of superheat. These alloys were solution treated at $1120^{\circ} \mathrm{C}$ and $1180^{\circ} \mathrm{C}$ for $2 \mathrm{~h}$ followed by air cooling before aging process at $845^{\circ} \mathrm{C}$ for $24 \mathrm{~h}$. and investigated that The $\mathrm{V}_{\mathrm{f}}$ of TCP (Tetragonal Close Packed) phases decreases as the solution treatment temperature increases.

The grain size of aged specimens treated at $1180^{\circ} \mathrm{C}$ was found to be coarser than that treated at $1120^{\circ} \mathrm{C}$. Hardness values of aged alloys treated at $1120^{\circ} \mathrm{C}$ were lower than those measured for $1180^{\circ} \mathrm{C}$ treated alloys. The corroded surfaces were examined by the light microscope. Results obtained revealed that the corrosion rate of the aged alloys treated at $1120^{\circ} \mathrm{C}$ was much higher than that of aged alloys treated at $1180^{\circ} \mathrm{C}$. Rates of corrosion were monitored based on ICP-AES (inductively coupled plasma atomic emission spectrometry) method and alloys in $1.0 \mathrm{M}$ $\mathrm{H}_{2} \mathrm{SO}_{4}$ solution at $25^{\circ} \mathrm{C}$. The amount of nickel released into the corrosive medium was taken as a measure of the corrosion rate. At the same temperature, alloys with fine microstructure were found to resist corrosion compared to those with coarse microstructure. The $\mathrm{V}_{\mathrm{f}}$ of primary $\gamma$ ' particles in aged alloys treated at $1120^{\circ} \mathrm{C}$ were higher than that of alloys treated at $1180^{\circ}$ C. However, Vf of secondary $\gamma^{\prime}$ precipitates in aged alloys treated at $1180^{\circ} \mathrm{C}$ was found to be larger than that in alloys treated at $1120^{\circ}$ C. R. Sunulahpasic et al. [12] have discussed the 
Nimonic $80 \mathrm{~A}$ is a wrought nickel base super alloy which 2. is particularly suitable for service under high stresses in temperature range from 600 to $750{ }^{\circ} \mathrm{C}$. This paper presents an analysis of fracture types after static tensile test at 3. different temperature range. The samples were tested at following temperatures $20,450,650,750$ and $850{ }^{\circ} \mathrm{C}$. It was found that Precipitation annealing leads to increasing of hardness and changes in grain size, Temperatures of solution annealing below $1080{ }^{\circ} \mathrm{C}$ lead to increased creep rate and higher temperatures caused an earlier failure with lower values of elongation. There is no significant change of tensile properties below temperature of $650{ }^{\circ} \mathrm{C}$. The microstructure examined on an optical microscope and scanning electron microscopy is a typical austenitic structure with twins and carbides at boundaries and inside the grains.

\section{PROPOSED WORK FROM LITERATURE}

On the bases of the literature survey, it is clear to do some heat treatments on the material to improve its mechanical and physical properties. A special treatment called ageing is proposed to be done on the supper-alloys. Natural aging: meaning that the precipitates form at room temperature, in some applications, naturally aging alloys may be stored in a freezer to prevent hardening until after further operations-assembly of rivets, for example, may be easier with a softer part. Artificial aging: when precipitates only form at elevated temperatures. Two types of heat treatment are usually recommended for bars, forgings, and flash-welded rings of Nickel-base super alloys. [13] These being solution heat-treatment (annealed); and (ii) precipitation heat treatment (aged). In the solution heattreatment process the specimen is heated to a temperature within the range $927^{\circ} \mathrm{C}-1010^{\circ} \mathrm{C}\left(1700^{\circ} \mathrm{F}-1859^{\circ} \mathrm{F}\right)$, holding at the selected temperature to within $+14^{\circ} \mathrm{C}$ $\left(+25^{\circ} \mathrm{F}\right)$ for a time commensurate with the cross-sectional thickness and cooling at a rate equivalent to air cooling or faster. This leads to a hardness of $R_{c}=12-15$. In the precipitation heat-treatment (aged) process, the specimen is heated to a temperature within the range $718^{\circ} \mathrm{C}-760^{\circ} \mathrm{C}$ $\left(1325-1400^{\circ} \mathrm{F}\right)$, holding at the selected temperature to within $+8^{\circ} \mathrm{C}\left(+15^{\circ} \mathrm{F}\right)$ for approximately $8 \mathrm{~h}$, cooling at a rate of $55^{\circ} \mathrm{C}+8^{\circ} \mathrm{C}\left(100^{\circ} \mathrm{F}+15^{\circ} \mathrm{F}\right)$ degrees per hour to a temperature within the range $621^{\circ} \mathrm{C}-649^{\circ} \mathrm{C}\left(1150^{\circ} \mathrm{F}-\right.$ $\left.1200^{\circ} \mathrm{F}\right)$, holding at the selected temperature to within $+8^{\circ} \mathrm{C}\left(+15^{\circ} \mathrm{F}\right)$ for approximately $8 \mathrm{~h}$ and then air cooling instead of $55^{\circ} \mathrm{C}\left(100^{\circ} \mathrm{F}\right)$ degrees per hour cooling rate to $621^{\circ} \mathrm{C}-649^{\circ} \mathrm{C}\left(1150^{\circ} \mathrm{F}-1200^{\circ} \mathrm{F}\right)$, the product may be furnace cooled at any rate provided that the Time at $621^{\circ} \mathrm{C}$ $-649^{\circ} \mathrm{C}\left(1150^{\circ} \mathrm{F}-1200^{\circ} \mathrm{F}\right)$ is adjusted to give a total precipitation heat-treatment time of approximately $18 \mathrm{~h}$. This usually leads to hardness of $R_{c} 41-43$. [14]

\section{RESULTS}

1. The above problem has been addressed partially by some of the authors as discussed in the literature review; still it is felt that there is need of more investigation to control the above process by using aging at different temperature for more duration.
It is also found that the effect of process on microstructure and mechanical properties depends only on temperature, time and quenching medium.

3. In the present work, effect of ageing on microstructure and mechanical properties of super alloy of nickel based alloy will be studied so as to improve the hardness, strength and other mechanical properties of the nickel based super alloy to withstand the high pressure and temperature at the inlet of the turbine by using some special heat treatment technique or process for super alloy to its micro-structural properties and low melting points.

\section{REFERENCES}

[1] I.A. Choudhury, M.A. El-Baradie, (1998) "Machine Ability Of Nickel Base Super-alloy:General Review", Journal Of Material Processing Technology,1998, 77, 278-284.

[2] D.U. Furrer, R. Shankar, and C. White (2003) "Optimizing The Heat Treatment of Ni-Based Super-alloy Turbine Discs "Applied Technology, 2003, 32-34.

[3] Panyawat Wangyao, Gobboon Lothongkum, “ Effect Of Heat Treatments After Hip Process On Microstructure Refurbishment In Cast Nickel-Based Super-alloy, In-738" Journal Of Metals, Materials And Minerals, 2005,15,2, 69-79,

[4] Tresa M. Pollock, Sammy Tin, "Nickel-Based Super-alloy for Advanced Turbine Engines: Chemistry, Microstructure, and Properties" Journal of Propulsion and Power, 2006, 22, 361-374.

[5] Neal D. Evans, Philip J. Maziasz and John J. Truhan,"Phase Transformations during Service Aging Of Nickel Phase Transformations during Service Aging Of Nickel", The Minerals, Metals \& Materials Society TN, 2008, 37841-6376

[6] Timothy P. Gabb1, John Gayda1, (2008) "The Effects of Heat Treatment And Microstructure Variation On Disk Supper Alloy Properties At High Temperature", TMS (The Minerals, Metals And Material Society). 2008, 121-130.

[7] L.A. Dobrzañski. Reimann, G. Krawczyk, (2008) "Influence Of The Ageing On Mechanical Properties Of The Aluminum Alloy Alsi9mg", Archives Of Materials Science And Engineering, 2008, $31,37-40$

[8] Zdenek Jonsta, Petr Jonsta, Jana Dobrovska, Eva Mazancova,"Effect Of Heat Treatment On The Structure Of In 713lc", Roznov Pod Radhostem, Czech Republic, Eu 18. - 2010.

[9] Mohamed Retima, Saida Bouyegh, Hacene Chadli,"Effect Of Heat Treatment On The Microstrucral Evolution Of The Nickel Based Super alloy", Association Of Metallurgical Engineers Of Serbia Ames Scientific Paper Udc: 669.245.057.,2011.

[10] Nader El-Bagoury,"Microstructure And Mechanical Properties Of Aged Nickel Base Super-alloy Archives Of Applied Science Research", 2011, 3 (2): 266-276

[11] N. El-Bagoury, Mohammed A. Amin, Q. Mohsen1,“ Effect Of Various Heat Treatment Conditions On Microstructure, Mechanical Properties And Corrosion Behavior Of Ni Base Super-alloy”, Int. J. Electrochem. Sci., 2011,6 6718 - 6732 .

[12] R. Sunulahpasic, M. Oruc, "Effect Of Temperature On Mechanical Properties And Type Of Fracture Of Super-alloy Nimonic 80a" ,Metabk, 2011, 50(3) 155-158

[13] N. El-Bagoury, Q. Mohsen, "Gamma Prime And Tcp Phases And Mechanical Properties Of Thermally Exposed Ni Base Super Alloy", Journal Of Phase Transition,2011, DOI: 10.1080/01411594.2011.582379.

[14] Alice Dumont, Loic Naze, "Investigation Of Heat Treatment Parameters Effect On The Microstructure And On The Mechanical Properties Of A Powder Metallurgy Nickel-Base Super-alloy" ,Brno, Czech Rep.,2012. 